\title{
Three-Dimensional Spheroid Cell Model of In Vitro Adipocyte Inflammation
}

\author{
Paul A. Turner, PhD, ${ }^{1}$ Yi Tang, $P h D,{ }^{2}$ Stephen J. Weiss, MD, ${ }^{2}$ and Amol V. Janorkar, $\mathrm{PhD}^{1}$
}

To improve treatment of obesity, a contributing factor to multiple systemic and metabolic diseases, a better understanding of metabolic state and environmental stress at the cellular level is essential. This work presents development of a three-dimensional (3D) in vitro model of adipose tissue displaying induced lipid accumulation as a function of fatty acid supplementation that, subsequently, investigates cellular responses to a proinflammatory stimulus, thereby recapitulating key stages of obesity progression. Three-dimensional spheroid organization of adipose cells was induced by culturing 3T3-L1 mouse preadipocytes on an elastin-like polypeptide-polyethyleneimine (ELP-PEI)-coated surface. Results indicate a more differentiated phenotype in 3D spheroid cultures relative to two-dimensional (2D) monolayer analogues based on triglyceride accumulation, CD36 and CD40 protein expression, and peroxisome proliferator-activated receptor- $\gamma$ (PPAR- $\gamma$ ) and adiponectin mRNA expression. The 3T3-L1 adipocyte spheroid model was then used to test the effects of a proinflammatory microenvironment, namely maturation in the presence of elevated fatty acid levels followed by acute exposure to tumor necrosis factor alpha (TNF- $\alpha)$. Under these conditions, we demonstrate that metabolic function was reduced across all cultures exposed to TNF- $\alpha$, especially so when pre-exposed to linoleic acid. Further, in response to TNF- $\alpha$, enhanced lipolysis, monitored as increased extracellular glycerol and fatty acids levels, was observed in adipocytes cultured in the presence of exogenous fatty acids. Taken together, our 3D spheroid model showed enhanced adipogenic differentiation and presents a platform for elucidating the key phenotypic responses that occur in pro-inflammatory microenvironments that characterize obesogenic states.

\section{Introduction}

$\mathbf{I}$ N RECENT DECADES, obesity has increased steadily within the United States, thereby contributing to multiple systemic and metabolic diseases in men and women of all ages, races, and ethnicities. ${ }^{1-3}$ In obese individuals, diets rich in carbohydrates and $\omega-6$ fatty acids, but poor in antioxidants and $\omega-3$ fatty acids, ${ }^{4}$ combined with a sedentary lifestyle, have been associated with chronic, low-grade systemic inflammation and overproduction of cytokines such as tumor necrosis factor alpha (TNF- $\alpha$ ), interleukin (IL)-1, and IL$6^{5-8}$ These pro-inflammatory events have been proposed to result in the dysregulation of fatty acid metabolism (hyperlipidemia), glucose metabolism (hyperglycemia), and insulin resistance. ${ }^{6}$ Though common treatment for obesity involves a calorie-restricted diet and exercise, ${ }^{9}$ an optimal solution in severely obese cases would ideally include intervention at the cellular level. Indeed, such a goal has motivated studies aimed at characterizing the mechanisms regulating adipogenesis and inflammatory responses using various in vivo and in vitro model systems. ${ }^{10-16}$

In keeping with the ability of fat tissue to respond to changes in fatty acid composition and pro-inflammatory stimuli, mature adipocytes express a number of plasma membrane-associated transporters, immune-related receptors, and intracellular signaling mediators that orchestrate responses to their changing microenvironment. For example, the transmembrane fatty acid transporter (FAT), CD36, is expressed by differentiated adipocytes and has been shown to mediate fatty acid uptake and glucose homeostasis via insulin sensitization ${ }^{17}$ as well as fatty acid egress and lipolysis. ${ }^{18}$ Likewise, CD40, a member of the TNF receptor superfamily, is expressed during adipose differentiation and has been shown to modulate the adipocyte inflammatory response and insulin resistance via an interaction with surrounding immune cells. ${ }^{19,20}$ In terms of intracellular mediators, peroxisome proliferator-activated receptor- $\gamma$ (PPAR- $\gamma$ ) has been established as a primary regulatory gene that is responsible for adipocyte differentiation ${ }^{21-23}$ and increased triglyceride accumulation, ${ }^{14}$ while the expression and secretion of adiponectin has been shown to be important for glucose homeostasis. ${ }^{14}$ Finally, the fatty acid class, particularly the degree of saturation, has been found to influence inflammatory signaling in 3T3 adipocytes by modulating TNF- $\alpha$ and IL-10 secretion, ${ }^{24}$ NF- $\kappa$ B activation, ${ }^{24,25}$ and PPAR- $\gamma$ activation. ${ }^{26,27}$ Taken together, the fatty acid

\footnotetext{
${ }^{1}$ Department of Biomedical Materials Science, School of Dentistry, University of Mississippi Medical Center, Jackson, Mississippi.

${ }^{2}$ Life Sciences Institute, University of Michigan, Ann Arbor, Michigan.
} 
FIG. 1. Timeline of cell culture activities performed in study. Color images available online at www .liebertpub.com/tea

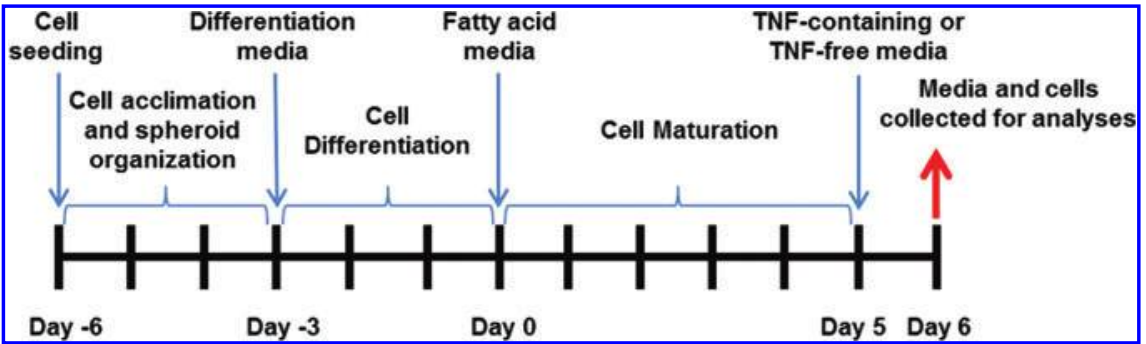

uptake via the CD36 transporters and their intracellular processing, activation of genes responsible for adipogenic differentiation, and the subsequent interaction of differentiated adipocytes with the surrounding microenvironment are important factors that should be recapitulated in models that are designed to study adipogenic mechanisms and inflammatory responses.

The challenges posed for accurately capturing an inflammatory response require a faithful replica of adipose physiology. However, most in vitro models of adipose tissue function involve culturing cells as two-dimensional (2D) monolayers atop rigid substrata that fail to recapitulate the complex three-dimensional (3D) histology found in vivo. ${ }^{14,18,24,28-33}$ Moreover, despite the known role of fatty acids in inflammatory signaling, ${ }^{24-27}$ no studies have been designed to characterize the effect of TNF- $\alpha$ exposure on adipocytes that have undergone maturation in the presence of elevated fatty acid levels. To address these issues, we have engineered a 3D spheroid model of adipose tissue by using a copolymer of elastin-like polypeptide (ELP) and polyethyleneimine (PEI) as a coating substrate to induce adipocyte spheroid formation. ${ }^{34}$ Given that elastin is a significant structural component of adipose tissue, ${ }^{35}$ a genetically engineered version of mammalian elastin, ELP, provides a physiologically relevant substratum that also allows tight control over molecular weight and structure, thereby minimizing batch-to-batch variations. Further, the ELP molecule used in our study benefits from having two reaction sites (i.e., at the $\mathrm{C}$ and $\mathrm{N}$ termini), thus limiting the potential for complex side reactions and network formation during the ELP-PEI conjugation process.

To accurately represent the pathophysiology of adiposity while addressing experimental and logistical demands (Fig. 1), we exposed the maturing 3T3-L1 spheroid cultures to physiologically relevant fatty acid levels ${ }^{36}$ for culture periods of 5 days. Here, we provided the maturing cells with key extracellular fatty acids representing clinically and nutritionally relevant classes (saturated, monounsaturated, and polyunsaturated) implicated in influencing adipogenesis and inflammation (Table 1) to simulate the effects of differential dietary intake on physiological cell conditioning. Following this regimen, we exposed the fatty acidexposed adipocytes to an acute dose of TNF- $\alpha$ to provoke an inflammatory response, simulating that of chronic obe- sity. Using this system, we have characterized the phenotypic and genotypic changes induced by the adipocyte inflammatory response.

\section{Materials and Methods}

\section{Expression, purification, and chemical modification of ELP}

ELP with a primary sequence [Valine-Proline-GlycineValine-Glycine $]_{40}$ was produced in a suspension culture of Escherichia coli and purified by an inverse transition temperature method. ${ }^{37}$ The purified ELP (molecular weight $=$ $17,000 \mathrm{Da})$ was chemically conjugated to branched PEI (molecular weight $=800$ Da; Sigma, St. Louis, MO) using carbodiimide chemistry as previously described. ${ }^{34,38}$

\section{ELP-PEl coating}

ELP-PEI coating masks the underlying adherent tissue culture polystyrene (TCPS), thereby altering cell morphology and differentiation. ${ }^{34}$ ELP-PEI conjugate was adsorbed to 24-well TCPS plates at a concentration of $5 \mathrm{~mol} \%$, previously identified as optimal for spheroid formation in 3T3L1 mouse preadipocytes. ${ }^{34}$

\section{T3-L1 cell culture}

3T3-L1 mouse preadipocytes ${ }^{39}$ were obtained from American Type Culture Collection (ATTC, Manassas, VA). 3T3-L1 mouse preadipocytes (passage 7-13) were cultured in highglucose (4.5 g/L) Dulbecco's Modified Eagle Medium (DMEM; Invitrogen, Carlsbad, CA) supplemented with $10 \%$ calf serum and $100 \mathrm{U} / \mathrm{mL}$ penicillin- $100 \mu \mathrm{g} / \mu \mathrm{L}$ streptomycin at $5 \% \mathrm{CO}_{2}$ and $37^{\circ} \mathrm{C}$ and harvested before reaching $70 \%$ confluence.

3T3-L1 mouse preadipocytes $(50,000$ cells per well of a $24-$ well plate; 26,000 cells $/ \mathrm{cm}^{2}$ ) were cultured either for 3 days atop uncoated TCPS to allow cells to reach confluence as a 2D monolayer or for 3 days atop ELP-PEI-coated TCPS to generate 3D spheroids. Subsequently, cells were differentiated for 3 days using DMEM supplemented with $10 \%$ fetal bovine serum (FBS), $1 \mu \mathrm{M}$ dexamethasone, $0.5 \mathrm{mM}$ IBMX, and $0.1 \mathrm{U} /$ $\mathrm{mL}$ insulin. ${ }^{34}$ After differentiation, cells were fed control or

Table 1. Fatty Acid Treatments Applied During Adipocyte Maturation

\begin{tabular}{lll}
\hline Fatty acid class & \multicolumn{1}{c}{ Selected fatty acid } & Dietary source $^{44}$ \\
\hline Saturated & $\mathrm{SA}(\mathrm{C} 18: 0) \mathrm{CH}_{3}\left(\mathrm{CH}_{2}\right)_{16} \mathrm{COOH}$ & Meat and chocolate \\
Monounsaturated $(\omega-9)$ & $\mathrm{OA}(\mathrm{C} 18: 1) \mathrm{CH}_{3}\left(\mathrm{CH}_{2}\right)_{7} \mathrm{CH}=\mathrm{CH}\left(\mathrm{CH}_{2}\right)_{7} \mathrm{COOH}$ & Olive oil and seed oils \\
Polyunsaturated $(\omega-3)$ & $\mathrm{LA}(\mathrm{C} 18: 2) \mathrm{CH}_{3}\left(\mathrm{CH}_{2}\right)_{4}(\mathrm{CH}=\mathrm{CHCH})_{2}\left(\mathrm{CH}_{2}\right)_{6} \mathrm{COOH}$ & Vegetable oil and corn oil
\end{tabular}

LA, linoleic acid; OA, oleic acid; SA, stearic acid. 
experimental medium for 5 days. Half of the media volume was changed every $48 \mathrm{~h}$. Control medium was prepared by supplementing DMEM with $10 \%$ FBS and $2 \%$ bovine serum albumin (BSA; Sigma). The control medium was sonicated for $45 \mathrm{~min}$ at $40^{\circ} \mathrm{C}$, cooled to $4^{\circ} \mathrm{C}$, sterile filtered, and added with $0.2 \mathrm{U} / \mathrm{mL}$ insulin and $100 \mathrm{U} / \mathrm{mL}$ penicillin $-100 \mu \mathrm{g} / \mathrm{mL}$ streptomycin. Fatty acid-supplemented medium was prepared by including $0.5 \mathrm{mM}$ of linoleic acid (LA), oleic acid (OA), or stearic acid (SA) in the control medium. The entire medium was sonicated at $40^{\circ} \mathrm{C}$ for $45 \mathrm{~min}$. After cooling to $4^{\circ} \mathrm{C}$, the medium was supplemented with $0.2 \mathrm{U} / \mathrm{mL}$ insulin and $100 \mathrm{U} /$ $\mathrm{mL}$ penicillin-100 $\mu \mathrm{g} / \mathrm{mL}$ streptomycin. Fatty acid loading efficacy was verified by gas chromatography (GC) as described elsewhere. ${ }^{34}$

After an 11-day culture period, cells were incubated in TNF-free media (DMEM $+10 \% \mathrm{FBS}+$ antibiotics) or media containing $125 \mathrm{ng} / \mathrm{mL}$ mouse TNF- $\alpha$ (Sigma). After $24 \mathrm{~h}$, media and lysate samples were collected for further analy- ses. A timeline for the experimental protocols is shown in Figure 1.

\section{Imaging and live/dead assay}

An IX-81 microscope (Olympus, Center Valley, PA) was used to image cells with ImageJ digital analysis software used to quantify spheroid dimensions. Live/Dead assay was performed as per the manufacturer's protocol (Invitrogen) on $2 \mathrm{D}$ and $3 \mathrm{D}$ cultures on day 3 (Fig. 2).

\section{Biochemical analyses}

After exposure to TNF-free or TNF- $\alpha$ containing media, 3T3-L1 monolayers or spheroids were recovered by trypsinization. Aliquots were centrifuged for $2 \mathrm{~min}$ at $1000 \mathrm{rpm}$, resuspended in PBS, and sonicated for $30 \mathrm{~s}$ at $10 \%$ amplitude using a Branson Digital Sonifier 450 (Danbury, CT). Protein and intracellular triglyceride content were analyzed
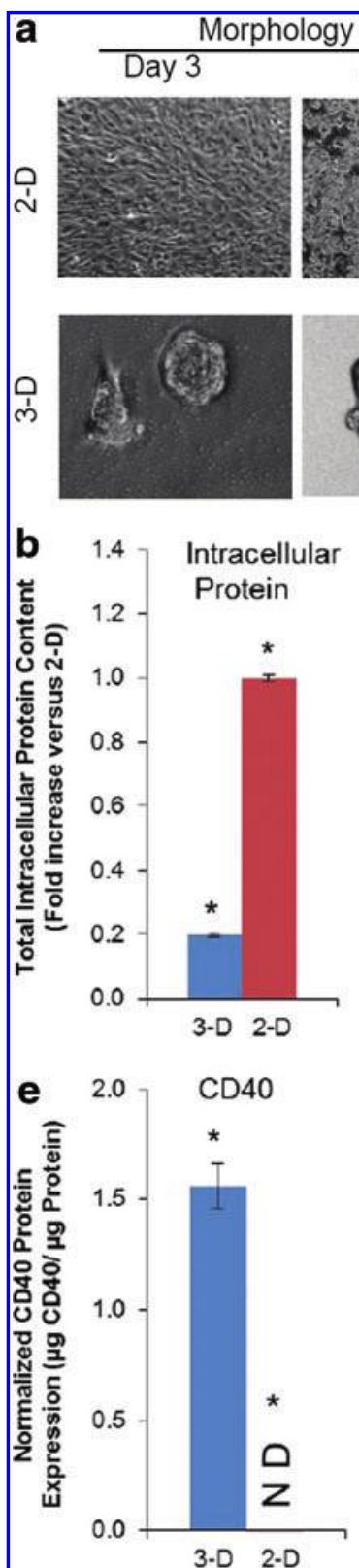
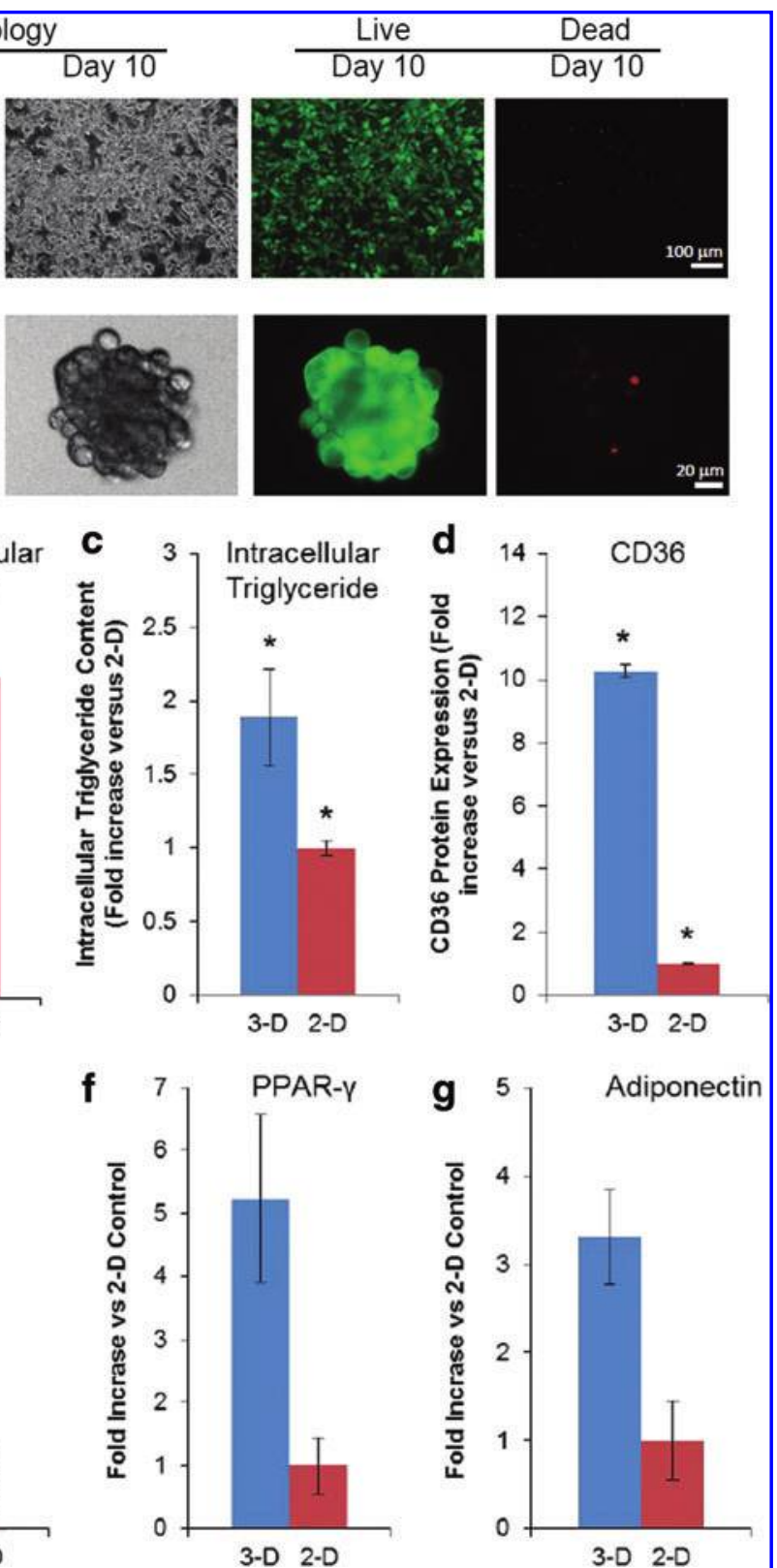

FIG. 2. Comparison of phenotypic and genotypic markers of adipogenesis demonstrated by cells grown in 3D spheroid versus 2D monolayer morphology, including (a) bright field morphology and Live/Dead imaging, (b) total intracellular protein, (c) intracellular triglyceride content, (d) CD36 FAT protein expression, (e) CD40 protein expression, (f) PPAR- $\gamma$ mRNA expression, and (g) adiponectin mRNA expression. Blue bars $=$ 3D spheroid culture, Red bars $=2 \mathrm{D}$ monolayer culture. ND, not detected. $* p \leq 0.05$. Error bars represent $95 \%$ confidence intervals. 2D, two-dimensional; 3D, three-dimensional; FAT, fatty acid transporter; PPAR- $\gamma$, peroxisome proliferator-activated receptor- $\gamma$. Color images available online at www.liebertpub .com/tea 
FIG.3. 3T3-L1 adipocyte total protein content was reduced in cultures treated with TNF- $\alpha$. Total protein content of (a) 3D spheroid and (b) 2D monolayer 3T3-L1 adipocytes matured in presence of various fatty acids and then exposed to TNF- $\alpha$ free (blue bars) or $125 \mathrm{ng} / \mathrm{mL}$ TNF- $\alpha$ (red bars) media for $24 \mathrm{~h} .{ }^{*} p \leq 0.05$ versus Control; ${ }^{\top} p \leq 0.05$ versus equivalent TNF- $\alpha$ untreated culture; ${ }^{£, Q, \$} p \leq 0.05$ versus equivalent LA, OA, and SA treatment, respectively. Error bars represent $95 \%$ confidence intervals. LA, linoleic acid; OA, oleic acid; SA, stearic acid; TNF- $\alpha$, tumor necrosis factor alpha. Color images available online at www.liebertpub.com/tea

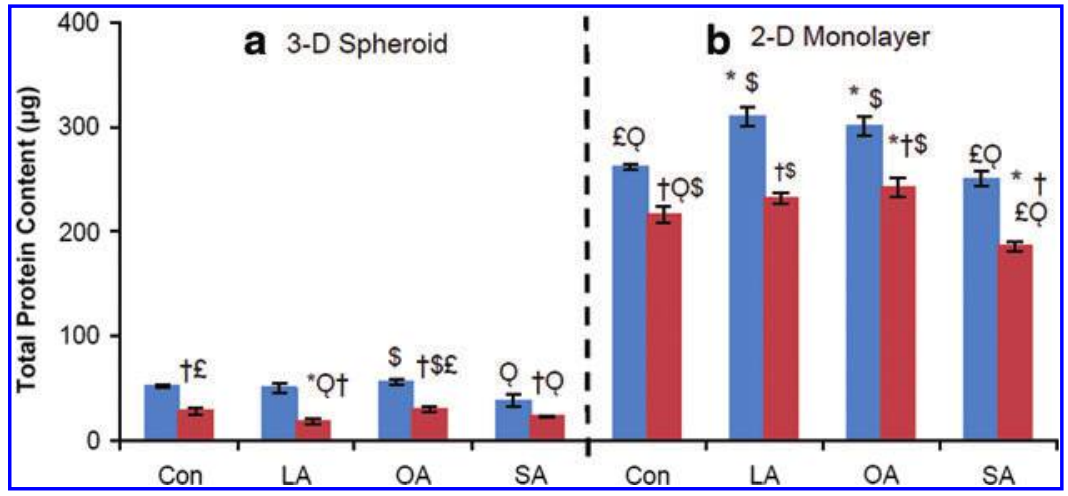

using assays performed as per the manufacturer's protocols and measured on an absorbance plate reader (Biotek ELx800, Winooski, VT) with a $540 \mathrm{~nm}$ filter. Assays were performed in triplicate for each sample taken from three experimental wells exposed to unique experimental media and culture conditions, yielding nine total measurements per condition. A chromatic BCA total protein assay (Thermo Fisher Scientific, Rockford, IL) was performed on cell lysates in accordance with the manufacturer's suggested protocol. Cell protein concentration was quantified by comparison against standard curves constructed from serially diluted albumin stocks. Total protein data were subsequently used to normalize individual markers collected with the other assays. Intracellular triglyceride accumulation and free glycerol were measured using a Serum Triglyceride Determination Kit (Sigma). Measurements were quantified by comparison with a glycerol standard solution (Sigma).

\section{Quantification of CD36 and CD40 proteins}

Levels of CD36 and CD40 were determined by ELISA (Abcam, Cambridge, MA) in accordance with the manufacturer's protocol. Assays were performed in triplicate for each culture condition, one sample per experimental well, yielding a total of three measurements per condition.

\section{MTT assay}

The influence of exogenous fatty acid and TNF- $\alpha$ treatments on cell viability/metabolism was quantified using a Molecular Probes MTT assay (Eugene, OR). All medium was removed at the time of the assay and replaced with $250 \mu \mathrm{L}$ control maintenance medium and $50 \mu \mathrm{L}$ of $12 \mathrm{mM}$ MTT assay. The cultures were then incubated at $37^{\circ} \mathrm{C}$ for $2 \mathrm{~h}$ to allow cells to metabolize the MTT to the reduced formazan. Excess media were removed, and the reduced tetrazolium salt was resolubilized using $1 \mathrm{~mL}$ DMSO. The stained solution was centrifuged at 14,000 rpm for $5 \mathrm{~min}$ to remove debris and absorbance measurements were determined at $540 \mathrm{~nm}$ using a Biotek plate reader, with nine measurements per condition. Wells containing only media and assay were read to acquire baseline measurements. The assay was performed for cultures grown in three wells under each culture condition (2D vs. 3D) and media treatment.

\section{GC analysis of fatty acid media}

GC was used to monitor fatty acid levels via binding with BSA as well as subsequent release after TNF- $\alpha$ treatment. Lipophilic elements were separated from whole media using Bligh-Dyer extraction technique. ${ }^{40}$ as previously described. ${ }^{34}$ Fatty acid content was quantified by logarithmic identification and integration of peaks produced by detector response relative to the internal standard. Individual components were identified and fit to standard curves produced from a Restek Marine Oil FAME Mix (Bellefonte, PA) consisting of 20 common lipid metabolites, including LA, $\mathrm{OA}$, and SA.

\section{Gene expression of 3T3-L1 adipocytes}

RNA was extracted from 3T3-L1 cultures using Qiagen (Germantown, MD) RNeasy Plus Mini kit after 5 days in
FIG. 4. Metabolic function of differentiated and matured 3T3-L1 adipocytes cultured as (a) 3D spheroid and (b) 2D monolayer was reduced by TNF- $\alpha$ treatment. MTT assay of 3T3-L1 adipocytes matured in presence of various fatty acids and then exposed to TNF- $\alpha$ free (blue bars) or $125 \mathrm{ng} / \mathrm{mL} \mathrm{TNF- \alpha} \mathrm{(red} \mathrm{bars)} \mathrm{media} \mathrm{for}$ 24 h. ${ }^{*} p \leq 0.05$ versus Control; $\bullet p \leq 0.05$ versus equivalent $2 \mathrm{D}$ monolayer culture; ${ }^{\dagger} p \leq 0.05$ versus equivalent TNF- $\alpha$-untreated culture; $£, \mathrm{Q}, \$ p \leq 0.05$ versus equivalent LA, OA, and SA treatment, respectively. Error bars represent 95\% confidence intervals. Color images available online at www.liebertpub.com/tea

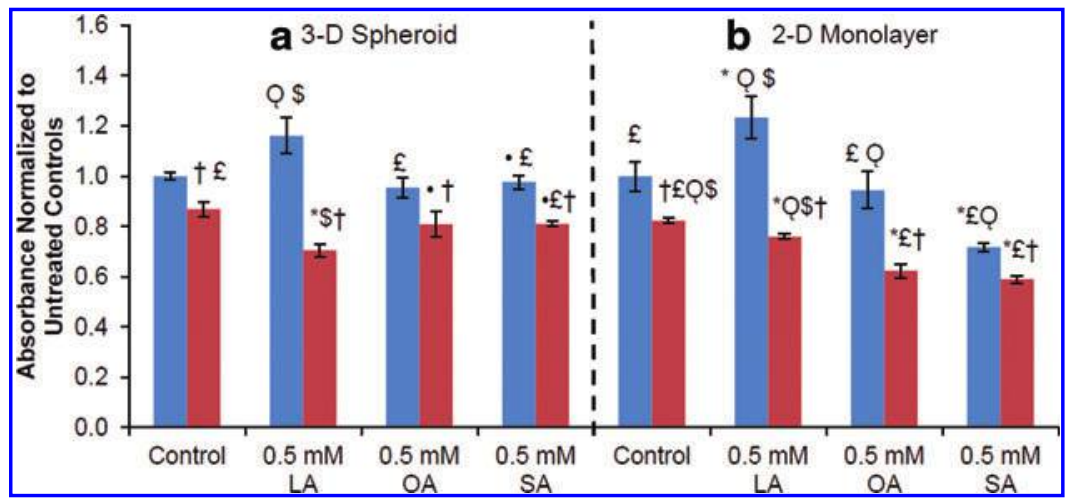




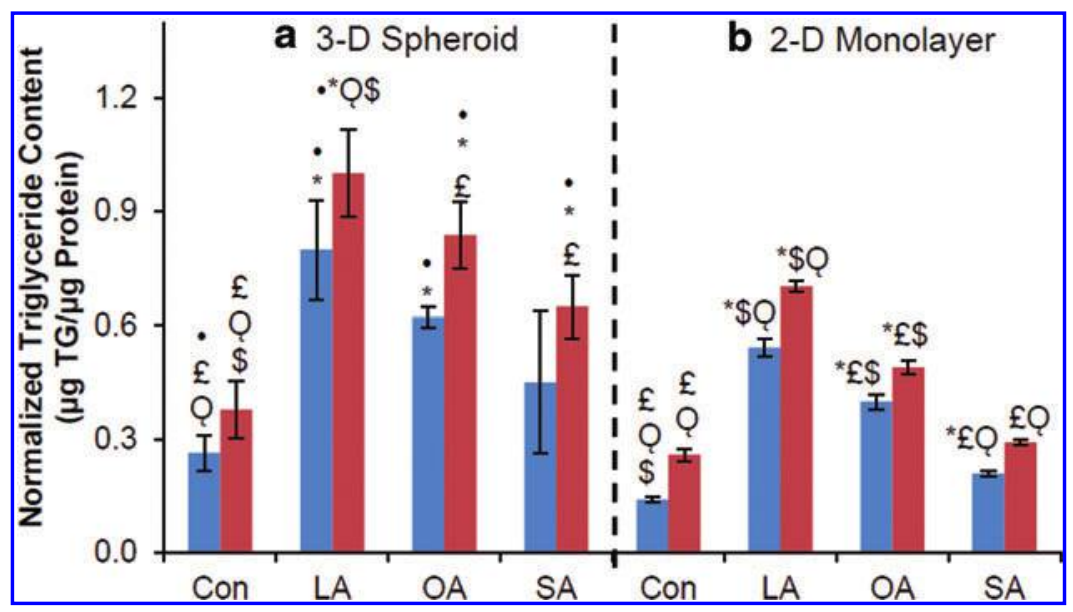

FIG. 5. Normalized triglyceride content in 3T3-L1 adipocytes was not downregulated by $\mathrm{TNF}-\alpha$ treatment. Intracellular triglyceride content of (a) 3D spheroid and (b) 2D monolayer 3T3-L1 adipocytes matured in presence of various fatty acids and then exposed to TNF- $\alpha$ free (blue bars) or $125 \mathrm{ng} / \mathrm{mL}$ TNF- $\alpha$ (red bars) media for 24h. * $p \leq 0.05$ versus Control; $\bullet p \leq 0.05$ versus equivalent $2 \mathrm{D}$ monolayer culture; $£, \mathrm{Q}, \$ p \leq 0.05$ versus equivalent LA, OA, and SA treatment, respectively. Error bars represent $95 \%$ confidence intervals.

Color images available online at www liebertpub.com/tea

control or fatty acid-supplemented media and after $24 \mathrm{~h}$ of exposure to TNF- $\alpha$. mRNA expression levels were determined relative to control GAPDH gene $\left(\Delta \Delta \mathrm{C}_{\mathrm{T}}\right)$ and expressed as mean fold change $\left(2^{\Delta \Delta \mathrm{CT}}\right) \pm 95 \% \mathrm{CI}$.

\section{Statistical analysis}

Quantitative results are reported as mean $\pm 95 \%$ confidence intervals. Statistical evaluation of the results was performed with analysis of variance followed by GamesHowell posthoc test for unequal variance. Values with $p \leq 0.05$ were deemed significantly different.

\section{Results}

When 3T3-L1 cells were induced to differentiate into mature adipocytes as either 2D monolayers or 3D spheroid cultures, distinct responses were observed with regard to changes in cell morphology as well as genotypic markers of adipogenesis (Fig. 2). Under standard conditions, cells in 2D monolayer cultures accumulated fat droplets over the 11-day culture period, but few cells showed unilocular fat droplets characteristic of complete adipocytic differentiation (Fig. 2a). In 3D cultures, the average size of newly formed spheroids of undifferentiated preadipocytes (i.e., $39 \pm 2 \mu \mathrm{m}$ ) increased $\sim 3.5$-fold in diameter over the 11-day culture period, reaching a final average size of $133 \pm 10 \mu \mathrm{m}$ (Fig. 2a). Importantly, and in contrast with $2 \mathrm{D}$ culture conditions, fat deposits in adipocyte spheroids were largely unilocular (Fig. 2a).

To begin characterizing changes in adipocyte differentiation markers, we noted that total intracellular protein levels were five-fold higher in 2D culture relative to 3D spheroids, reflecting the fact that cell number increased in monolayer culture until confluent conditions were reached as opposed to the growth-restricted spheroids. ${ }^{34,38}$ Specifically, within the first $72 \mathrm{~h}$ of culture, the 3D spheroid cultures displayed contact-inhibited growth arrest and cells in 2D cultures continued to proliferate until achieving confluence. Thus, at the time of differentiation on day -3 (Fig. 1), both 2D and $3 \mathrm{D}$ cultures were discouraged from further proliferation and were more susceptible to undergo differentiation. This process introduced significant differences in the total cell population, and, therefore, all markers of adipogenic differentiation were normalized to protein content. Using this baseline, triglyceride accumulation, indicative of adipogenic differentiation, increased almost two-fold in 3D spheroid cultures relative to $2 \mathrm{D}$ monolayers (Fig. 2c). CD36 FAT protein expression, a key regulator of fatty acid uptake, ${ }^{17,18}$ was also significantly upregulated almost 10 -fold in 3D spheroids versus 2D monolayers (Fig. 2d). Likewise, CD40, a cytokine receptor protein involved in adaptive immunity, ${ }^{19,20}$ was significantly increased in 3D spheroid cultures while remaining undetectable in 2D monolayers (Fig. 2e). In

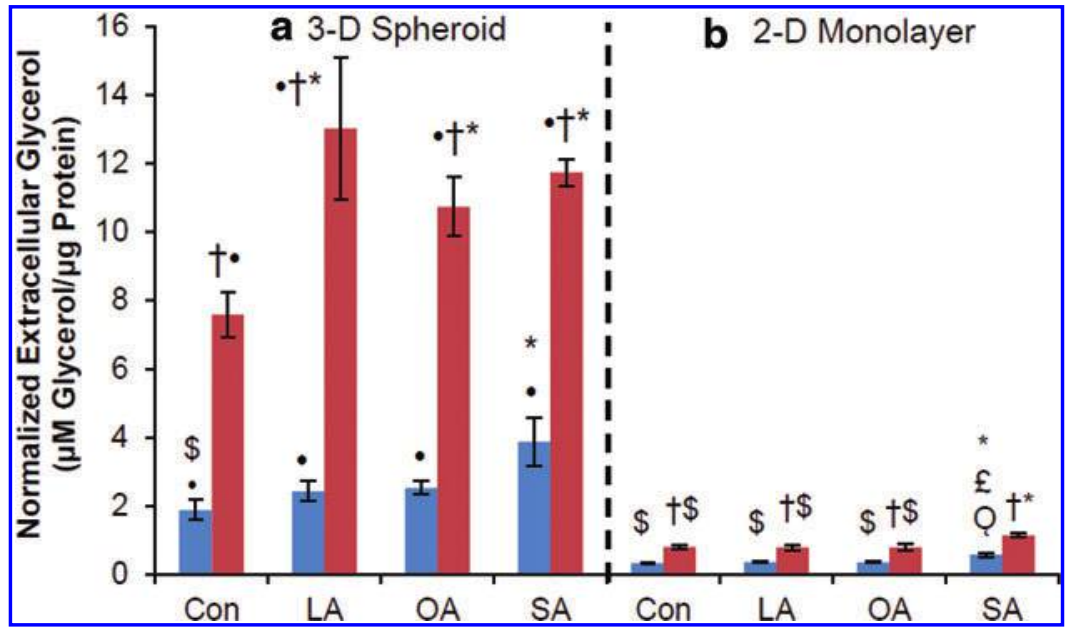

FIG. 6. TNF- $\alpha$ treatment triggered glycerol release by 3T3-L1 adipocytes. Glycerol release by (a) 3D spheroid and (b) 2D monolayer 3T3-L1 adipocytes matured in presence of various fatty acids and then exposed to TNF- $\alpha$-free (blue bars) or $125 \mathrm{ng} / \mathrm{mL} \mathrm{TNF-} \alpha$ (red bars) media for $24 \mathrm{~h}$. Changes in extracellular glycerol were measured with triglyceride assay and normalized to day 5 and 6 total protein data. $* p \leq 0.05$ versus Control; $\bullet p \leq 0.05$ versus equivalent $2 \mathrm{D}$ monolayer culture; ${ }^{\dagger} p \leq 0.05$ versus equivalent TNF- $\alpha$ untreated culture; ${ }^{£, \mathrm{Q}, \$} p \leq 0.05$ versus equivalent LA, OA, and SA treatment, respectively. Error bars represent $95 \%$ confidence intervals. Color images available online at www.liebertpub.com/tea 
FIG. 7. 3T3-L1 adipocytes released free fatty acid in response to TNF- $\alpha$ treatment. Gas chromatography data of extracellular fatty acid concentrations from cultures of (a) 3D spheroid and (b) 2D monolayer 3T3-L1 adipocytes matured in presence of various fatty acids and then exposed to TNF- $\alpha$ free (blue bars) or $125 \mathrm{ng} / \mathrm{mL} \mathrm{TNF- \alpha} \mathrm{(red} \mathrm{bars)}$ media for $24 \mathrm{~h}$. No significant fatty acid release detected in control 3D and 2D cultures. $\bullet p \leq 0.05$ versus equivalent $2 \mathrm{D}$ monolayer culture; ${ }^{\dagger} p \leq 0.05$ versus equivalent TNF- $\alpha$ untreated culture; ${ }^{£, \mathrm{O}, \$} p \leq 0.05$ versus equivalent LA, OA, and SA treatment, respectively. Error bars represent $95 \%$ confidence intervals. Color images available online at www.liebertpub.com/tea

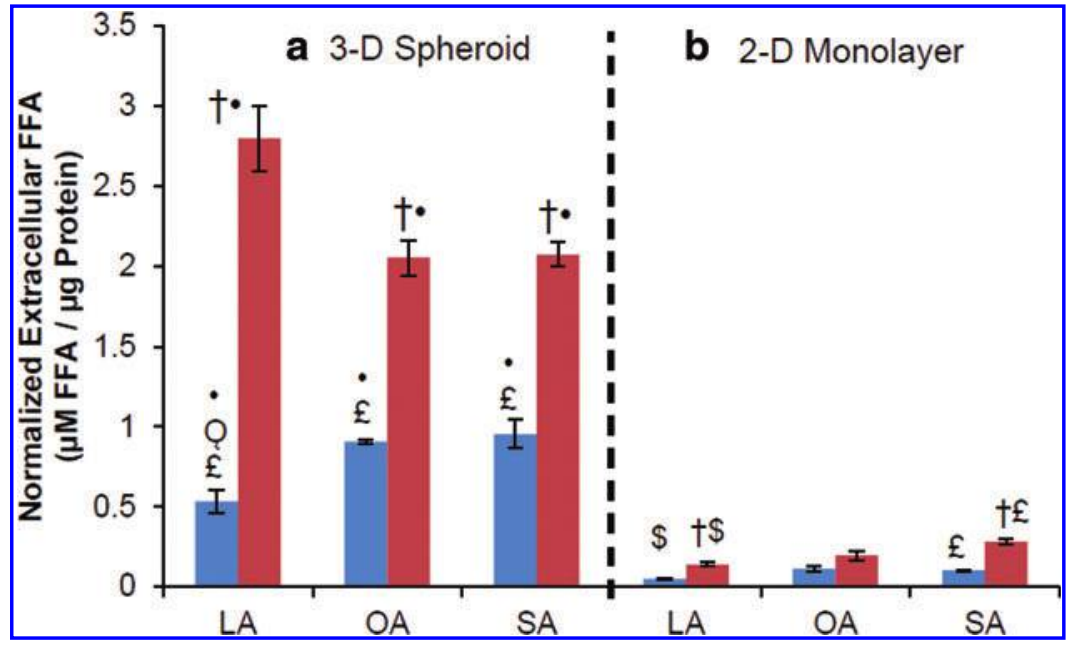

keeping with the superior characteristics of the spheroid culture system, PPAR- $\gamma$ mRNA levels were five-fold higher in $3 \mathrm{D}$ spheroid cultures relative to the 2D monolayers, whereas adiponectin expression was increased more than three-fold (Fig. 2f, g). Minimal changes in cell viability occurred under either $2 \mathrm{D}$ or $3 \mathrm{D}$ culture conditions with minimal cell death detected at any time point (Fig. 2a).

To next assess the responses of adipocytes cultured under 2D or 3D conditions to pro-inflammatory stimuli, cells were cultured in either control media or media supplemented with LA, OA, or SA and then incubated with or without TNF- $\alpha$ for an additional $24 \mathrm{~h}$ period. After fatty acid supplementation, the protein content of adipocytes cultured under either 3D or 2D conditions was comparable to controls (Fig. 3, blue bars). TNF- $\alpha$ treatment reduced total protein levels by $\sim 20 \%$ under all 2D monolayer culture conditions and $45 \%$ under all 3D spheroid culture conditions (Fig. 3, red bars), while this effect was exaggerated in LA-supplemented cultures. As TNF- $\alpha$ has been shown to impact cell viability and loss of metabolic function, ${ }^{28}$ we assessed the effect of TNF- $\alpha$ on our cultures using the MTT assay. Differentiated $3 \mathrm{D}$ and $2 \mathrm{D}$ cultures treated with TNF- $\alpha(125 \mathrm{ng} / \mathrm{mL})$ displayed reduction of $20-40 \%$ in metabolic function (Fig. 4). Again, this effect was exaggerated in LA-supplemented cultures. Three-dimensional spheroid cultures showed improved metabolic function/viability after exposure to TNF- $\alpha$ relative to the 2D monolayer cultures (Fig. 4).

Three-dimensional spheroid cultures displayed an enhanced intracellular triglyceride content after culture in each class of exogenous fatty acid treatment compared with cultures fed the control medium (Fig. 5a, blue bars). Specifically, basal triglyceride content was increased four, three, and two-fold by treatment with LA, OA, and SA, respectively. Triglyceride content in 2D monolayer cultures (Fig. 5b, blue bars) also exhibited a dependency on class of fatty acid treatment, but to a lesser degree than that observed in 3D spheroid cultures. By contrast, TNF- $\alpha$ treatment did not alter intracellular triglyceride content in 3D or 2D cultures at a statistically significant level (Fig. 5; $p>0.05)$.

As changes in total intracellular triglyceride content might not reflect rapid mobilization coupled with efficient uptake, we next assessed the possible effect of TNF- $\alpha$ on lipolysis under 3D versus 2D cultures by quantifying glycerol and fatty acid release. Extracellular glycerol levels were significantly upregulated under all 3D spheroid cultures after TNF- $\alpha$ exposure (Fig. 6a, red bars). By contrast, only small increases were observed in 2D cultures (Fig. 6b). Likewise,

FIG. 8. 3T3-L1 adipocyte expression of CD36 protein was unaffected by TNF- $\alpha$ treatment. ELISA assay of CD36 expression in (a) 3D spheroid and (b) 2D monolayer 3T3-L1 adipocytes matured in presence of various fatty acids and then exposed to TNF$\alpha$-free (blue bars) or $125 \mathrm{ng} / \mathrm{mL}$ TNF- $\alpha$ (red bars) media for $24 \mathrm{~h}$. $* p \leq 0.05$ versus Control; $\bullet p \leq 0.05$ versus equivalent $2 \mathrm{D}$ monolayer culture; ${ }^{£, Q, \$} p \leq 0.05$ versus equivalent LA, OA, and SA treatment, respectively. Error bars represent $95 \%$ confidence intervals. Color images available online at www.liebertpub.com/tea

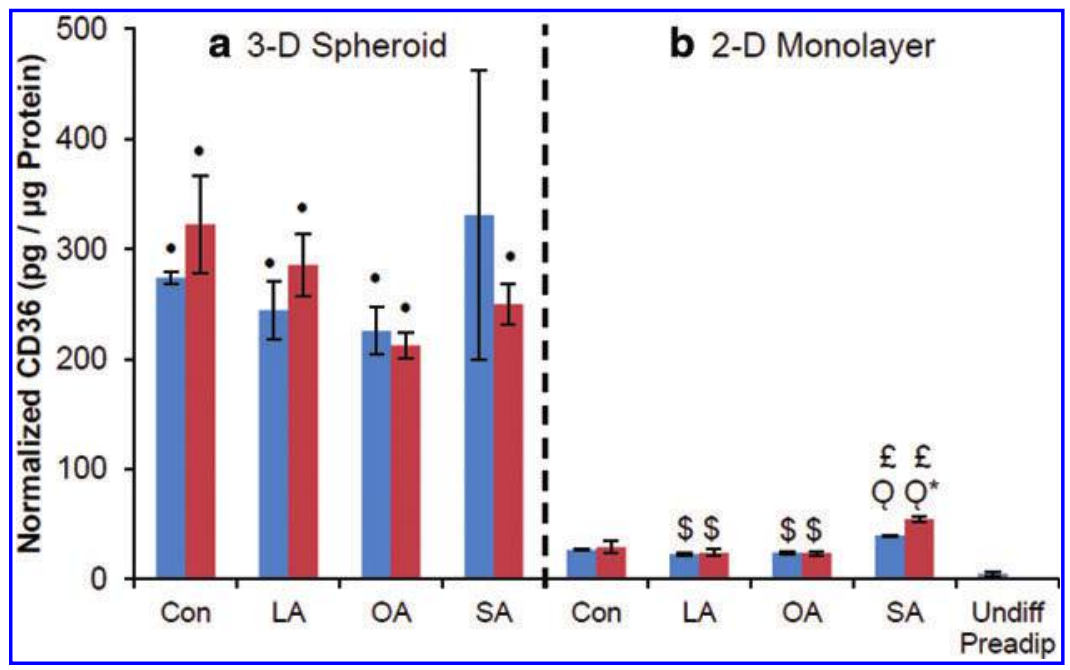




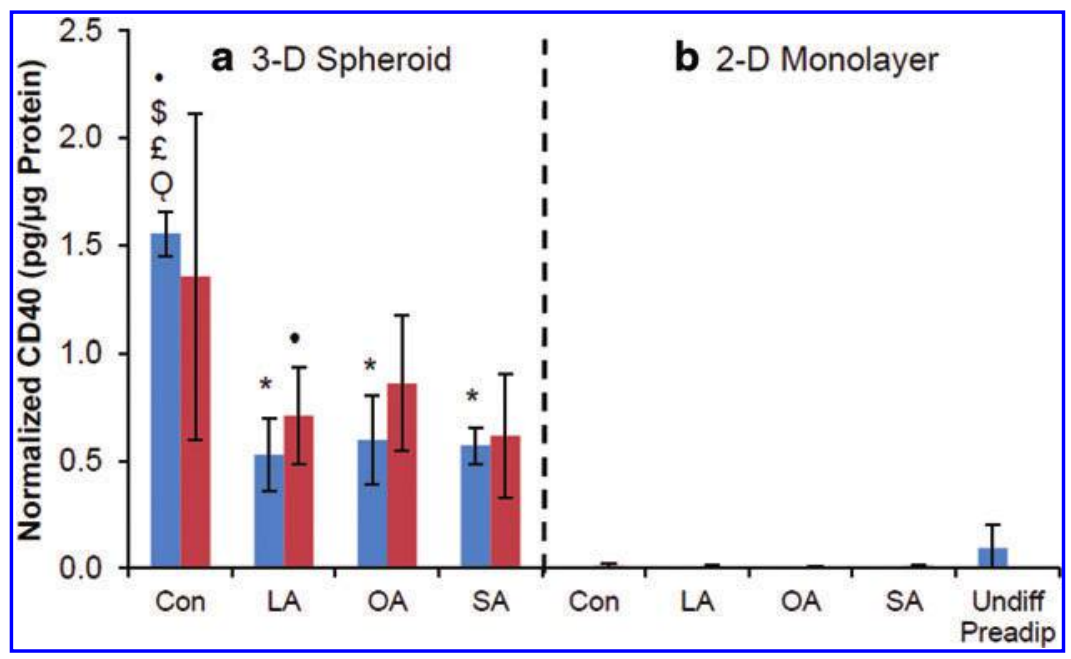

FIG. 9. 3T3-L1 adipocyte expression of CD40 protein was unaffected by TNF- $\alpha$ treatment. ELISA assay of CD40 expression in (a) 3D spheroid and (b) 2D monolayer 3T3-L1 adipocytes matured in presence of various fatty acids and then exposed to TNF$\alpha$ free (blue bars) or $125 \mathrm{ng} / \mathrm{mL}$ TNF- $\alpha$ (red bars) media for $24 \mathrm{~h}$. $* p \leq 0.05$ versus Control; $\bullet p \leq 0.05$ versus equivalent $2 \mathrm{D}$ monolayer culture; ${ }^{\mathfrak{\ell}, \mathrm{Q}, \$} p \leq 0.05$ versus equivalent LA, OA, and SA treatment, respectively. Error bars represent $95 \%$ confidence intervals. Color images available online at

extracellular free fatty acid levels also increased in TNF- $\alpha$ stimulated 3D cultures (Fig. 7a, red bars) with only blunted responses recorded in 2D cultures (Fig. 7b). Further, while fatty acid supplementation enhanced TNF- $\alpha$-mediated lipolysis relative to control 3D spheroid cultures (Figs. 6a and $7 a)$, similar effects were not observed in 2D monolayer cultures (Figs. 6b and 7b).

CD36 content was found to be greatly increased in 3D spheroid cultures after differentiation, but no significant differences were displayed after fatty acid treatment (Fig. $8 \mathrm{a}$, blue bars) or subsequent TNF- $\alpha$ exposure (Fig. 8a, red bars). In 2D culture, CD36 levels were only modestly increased relative to control 3T3-L1 cells and were not altered after TNF- $\alpha$ exposure (Fig. 9b). Likewise, CD40 was also upregulated across all 3D spheroid culture conditions relative to $2 \mathrm{D}$ monolayer cultures and undifferentiated 3T3-L1 cells (Fig. 9a, b). However, CD40 levels were significantly lower in all fatty acid-treated 3D cultures compared with control 3D culture, though significant differences were not detected between the individual fatty acid-supplemented culture conditions (Fig. 9a, blue bars). Similar to CD36, C40 protein expression was also unaffected by the subsequent TNF- $\alpha$ treatment in 3D spheroids (Fig. 9a, red bars).
To determine the impact of fatty acids and TNF on adipogenic programs at the level of gene expression, mRNA was collected from 3T3-L1 adipocytes cultured under 3D or 2D conditions and PPAR- $\gamma$ as well as adiponectin expression assessed by RT-PCR. No obvious differences were found in PPAR- $\gamma$ expression based on fatty acid treatment under 2D monolayer or 3D spheroid culture conditions (Fig. 10 , blue bars). By contrast, TNF- $\alpha$ treatment consistently reduced PPAR- $\gamma$ expression under all culture conditions (Fig. 10, red bars). Unlike PPAR- $\gamma$, adiponectin expression did not show a consistent trend in response to fatty acid supplementation or the TNF- $\alpha$ treatment (Fig. 11).

\section{Discussion}

Here, we report that expression of multiple adipogenic factors is significantly upregulated in the 3D spheroid model relative to standard 2D monolayer culture systems. These features highlight fundamental differences in cell behavior due to effects on both cell morphology and 3D organization, and they support the improved recapitulation of adipogenesis and metabolic function in the spheroid model. In vivo, obesogenic states expose adipocyte precursors as well as mature adipocytes to increased levels of fatty acids as well

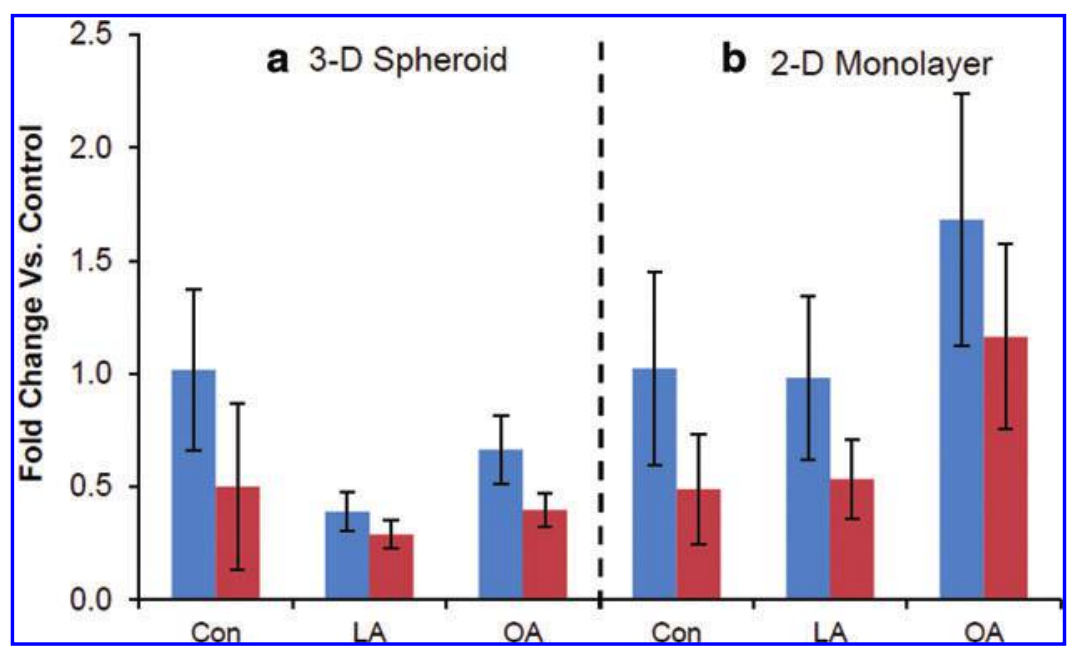

FIG. 10. PPAR- $\gamma$ mRNA expression from (a) 3D spheroid and (b) monolayer cultures of 3T3-L1 adipocytes matured in presence of various fatty acids and then exposed to TNF- $\alpha$ free (blue bars) or $125 \mathrm{ng} / \mathrm{mL}$ TNF- $\alpha$ (red bars) media for $24 \mathrm{~h}$. Error bars represent $95 \%$ confidence intervals. Color images available online at www.liebertpub.com/tea 
FIG. 11. Adiponectin mRNA expression from (a) 3D spheroid and (b) 2D monolayer cultures of 3T3-L1 adipocytes matured in presence of various fatty acids and then exposed to TNF- $\alpha$ free (blue bars) or $125 \mathrm{ng} / \mathrm{mL}$ TNF- $\alpha$ (red bars) media for $24 \mathrm{~h}$. Error bars represent $95 \%$ confidence intervals. Color images available online at www.liebertpub.com/tea

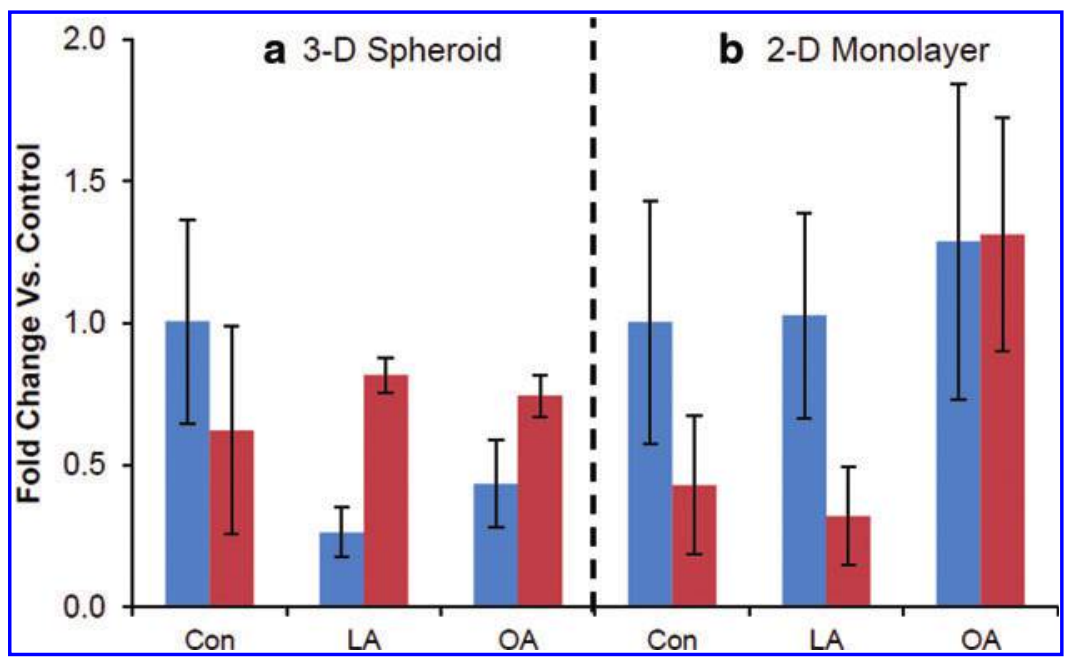

as pro-inflammatory cytokines. ${ }^{41,42}$ As such, we sought to assess the effect of fatty acid supplementation and TNF- $\alpha$ on adipocyte differentiation and function using 3T3-L1 cells cultured either as 3D spheroids or as standard 2D monolayers (summarized in Fig. 12).

Independent of the quantity of the fat present in the diet, the composition and nature of the fatty acids appear to influence human health. ${ }^{23,27,43}$ For example, a wide range of saturated and unsaturated fatty acids have been found to differentially interact with molecular sensors such as PPAR$\gamma$, a key operator in adipocyte differentiation and regulator of characteristic activities such as sensitivity to insulin, lipogenesis from fatty acids, and subsequent lipolysis of stored triglycerides. $^{23,27,44,45}$ Therefore, fatty acids representing different classes of nutritional classes, namely, LA (C18:2), OA (C18:1), and SA (C18:0), were selected for our study. LA is a polyunsaturated $\omega-6$ fatty acid that may be converted into arachidonic acid, which, in turn, may influence the intensity and duration of inflammatory processes by contributing to the formation of pro-inflammatory cytokines and eicosanoids. ${ }^{6} \mathrm{SA}$ is a saturated fatty acid that has been implicated in pathological insulin resistance in adipocytes due to oxidative stress induced during metabolism. ${ }^{43}$ As OA is a monounsaturated $\omega-9$ fatty acid, it served as a noninflammatory comparison in our study. Based on our results, polyunsaturated LA appears to be more efficiently converted into triglyceride relative to SA (Fig. 5). Interestingly, PPAR$\gamma$ and adiponectin gene expressions did not appear to be affected by fatty acid supplementation (Figs. 10 and 11, blue bars). In a comparative study, Xu et al. ${ }^{27}$ found unsaturated fatty acids, such as arachidonic acid, were effective agonists for PPAR- $\gamma$, while SA and OA had a lesser binding affinity. However, the effect of fatty acids on PPAR- $\gamma$ mRNA expression has not been previously reported. On the other hand, fatty acids have been reported to affect adiponectin expression, but only under specific conditions. For example, while Dordevic et al. ${ }^{46}$ and Bueno et al. ${ }^{47}$ showed no impact on adiponectin expression after a 4 or $48 \mathrm{~h}$ OA treatment period, Granados et al. ${ }^{48}$ reported a $25 \%$ increase in adiponectin expression after a $24 \mathrm{~h} \mathrm{OA}$ treatment. In our longterm studies (i.e., 5 day culture period of mature adipocytes with fatty acids), no consistent effects on adiponectin expression were observed.

When administered globally, TNF- $\alpha$ has been shown to induce lipolysis in human adipose tissue ${ }^{49}$ and a similar response has been modeled in vitro using cultures of
FIG. 12. (a) Mechanistic description of changes observed in TNF- $\alpha$ versus control media. (b) Flow-chart explaining inflammatory response of 2D monolayer and 3D spheroid cultures to TNF$\alpha$ treatment. Color images available online at www .liebertpub.com/tea
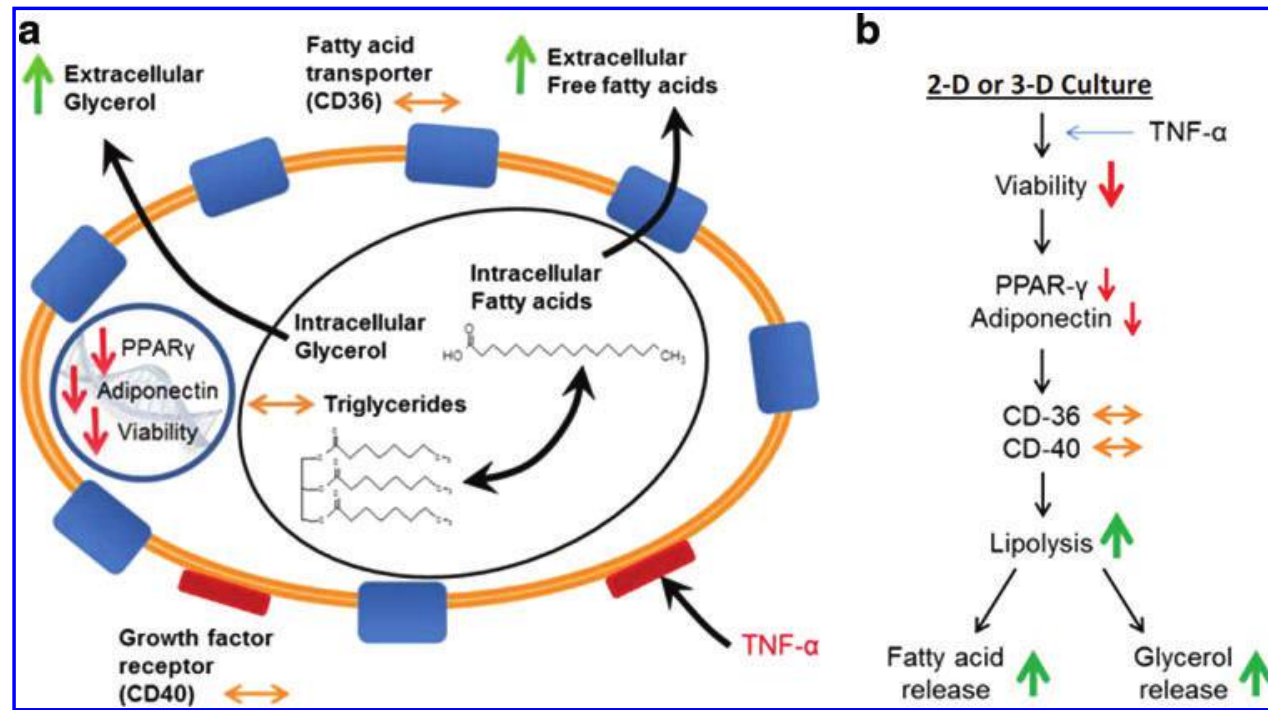
human, $^{28,29}$ rat, $^{30,31}$ and mouse 3T3-L1-derived ${ }^{14,17,18,24,32,50}$ adipocytes. In our study, reduced metabolic activity was observed across all cultures after TNF- $\alpha$ treatments as assessed by the MTT assay (Fig. 4), with proportional decreases in intracellular protein (Fig. 3). Significant increases in both extracellular glycerol (Fig. 6) and free fatty acids (Fig. 7) were found after TNF- $\alpha$ treatment. Expression of PPAR $-\gamma$ mRNA was also found to be downregulated after TNF- $\alpha$ treatment (Fig. 10). Taken together, these results indicate that after fatty acid supplementation and TNF- $\alpha$ treatment, the differentiated and maturing 3T3-L1 adipocytes assume a more pro-inflammatory state and respond by releasing products of lipolysis. It should be noted that while these effects were displayed in both the 2D monolayer and $3 \mathrm{D}$ spheroid cultures, the effects observed in the $3 \mathrm{D}$ spheroid cultures were significantly enhanced, possibly due to the increased expression of CD36 (Fig. 8). Curiously, the intracellular triglyceride content (Fig. 4) was not shown to be reduced after TNF- $\alpha$ exposure despite large increases in extracellular glycerol and fatty acids (Figs. 6 and 7). Published studies have typically associated TNF- $\alpha$ stimulation with lipolysis, ${ }^{28-33,50-53}$ and our own observations of increased extracellular lipolysis products (Figs. 6 and 7) corroborated those findings. However, previous studies ${ }^{18,28-33,50-53}$ did not measure intracellular triglyceride content but based their conclusions regarding lipolysis on extracellular glycerol measurements and/or gene expression. Most likely, the absence of significant changes in intracellular triglyceride content in response to $\mathrm{TNF}-\alpha$ reflects the rapid re-synthesis of triglycerides from glycerol reactants combined with existing or recycled fatty acid molecules from the surrounding media. In this regard, Beale et al. have proposed that such glycerol reactants could be produced by glyceroneogenesis and the production of new glycerol 3-phosphate from gluconeogenic precursors. ${ }^{54}$ This mechanism clearly warrants further investigation, perhaps by measuring glucose uptake, GLUT4 expression, or glucose metabolism.

\section{Conclusions}

We used our 3T3-L1 spheroid model of adipogenesis to test the effects of an inflammatory microenvironment, namely maturation in an environment of elevated fatty acids followed by acute TNF- $\alpha$ exposure. We observed that the cell metabolic function was reduced across all cultures exposed to $\mathrm{TNF}-\alpha$, and the loss was increased by pro-inflammatory LA treatment. Both extracellular glycerol and fatty acids, conventional markers of lipolysis, increased after TNF- $\alpha$ treatment, particularly in cultures matured with elevated fatty acid concentrations. These effects were also mirrored in the expression of PPAR- $\gamma$. Overall, the 3D spheroid model demonstrated enhanced adipocyte-specific function when exposed to fatty acids and TNF- $\alpha$ and provided an important system for future mechanistic investigations of the qualitative and quantitative effects of pro-inflammatory stimuli on adipocyte function.

\section{Acknowledgments}

Support from the School of Dentistry and the University of Mississippi Medical Center intramural research support programs and the National Science Foundation (Award No: $1033525)$ is gratefully acknowledged. The content is solely the responsibility of the authors and does not necessarily represent the official views of the National Science Foundation. This work made use of instruments in the Department of Biomedical Materials Science User Facility. The authors gratefully acknowledge the support and expertise provided by Dr. Rodney Baker and Ms. Chris Purser of the UMMC Department of Pharmacology and Toxicology.

\section{Disclosure Statement}

No competing financial interests exist.

\section{References}

1. Flegal, K.M., Carroll, M.D., Ogden, C.L., and Johnson, C.L. Prevalence and trends in obesity among US adults, 1999-2000. JAMA 288, 1723, 2002.

2. Mokdad, A.H., Serdula, M.K., Dietz, W.H., Bowman, B.A., Marks, J.S., and Koplan, J.P. The spread of the obesity epidemic in the United States, 1991-1998. JAMA 282, 1519, 1999.

3. Wang, Y., Beydoun, M.A., Liang, L., Caballero, B., and Kumanyika, S.K. Will all Americans become overweight or obese? estimating the progression and cost of the US obesity epidemic. Obesity 16, 2323, 2008.

4. Simopoulos, A.P. Evolutionary aspects of diet: essential fatty acids. In: Mostofsky, D.I., Yehuda, S., and Salem, N., eds. Fatty Acids: Physiological and Behavioral Functions. Totowa, NJ: Humana Press, 2001.

5. Tanzi, M.C., and Farè, S. Adipose tissue engineering: state of the art, recent advances and innovative approaches. Expert Rev Med Devices 6, 533, 2009.

6. Calder, P.C. n-3 Polyunsaturated fatty acids, inflammation, and inflammatory diseases. Am J Clin Nutr 83, S1505, 2006.

7. Pedersen, M., Bruunsgaard, H., Weis, N., Hendel, H.W., Andreassen, B.U., Eldrup, E., Dela, F., and Pedersen, B.K. Circulating levels of TNF-alpha and IL-6-relation to truncal fat mass and muscle mass in healthy elderly individuals and in patients with type-2 diabetes. Mech Ageing Dev 124, 495, 2003.

8. Hotamisligil, G.S., Arner, P., Caro, J.F., Atkinson, R.L., and Spiegelman, B.M. Increased adipose tissue expression of tumor necrosis factor-alpha in human obesity and insulin resistance. J Clin Invest 95, 2409, 1995.

9. Stein, C.J., and Colditz, G.A. The epidemic of obesity. J Clin Endocrinol Metab 89, 2522, 2004.

10. Gomillion, C.T., and Burg, K.J. Stem cells and adipose tissue engineering. Biomaterials 27, 6052, 2006.

11. Hemmrich, K., Meersch, M., Wiesemann, U., Salber, J., Klee, D., Gries, T., and Pallua, N. Polyesteramide-derived nonwovens as innovative degradable matrices support preadipocyte adhesion, proliferation, and differentiation. Tissue Eng 12, 3557, 2006.

12. Patel, P.N., Gobin, A.S., West, J.L., and Patrick, C.W., Jr. Poly(ethylene glycol) hydrogel system supports preadipocyte viability, adhesion, and proliferation. Tissue Eng 11, 1498, 2005.

13. Patrick, C.W. Breast tissue engineering. Ann Rev Biomed Eng 6, 109, 2004.

14. Shiomi, N., Maeda, M., and Mimura, M. Compounds that inhibit triglyceride accumulation and $\mathrm{TNF} \alpha$ secretion in adipocytes. J Biomed Sci Eng 4, 684, 2011.

15. von Heimburg, D., Zachariah, S., Heschel, I., Kuhling, H., Schoof, H., Hafemann, B., and Pallua, N. Human pre- 
adipocytes seeded on freeze-dried collagen scaffolds investigated in vitro and in vivo. Biomaterials 22, 429, 2001.

16. Wu, X., Black, L., Santacana-Laffitte, G., and Patrick, C.W. Preparation and assessment of glutaraldehyde-crosslinked collagen-chitosan hydrogels for adipose tissue engineering. J Biomed Mater Res Part A 81A, 59, 2007.

17. Kontrova, K., Zidkova, J., Bartos, B., Skop, V., Sajdok, J., Kazdova, L., Mikulik, K., Mlejnek, P., Zidek, V., and Pravenec, M. CD36 regulates fatty acid composition and sensitivity to insulin in 3T3-L1 adipocytes. Physiol Res 56, 493, 2007.

18. Zhou, D., Samovski, D., Okunade, A.L., Stahl, P.D., Abumrad, N.A., and Su, X. CD36 level and trafficking are determinants of lipolysis in adipocytes. FASEB J 26, 4733, 2012.

19. Poggi, M., Jager, J., Paulmyer-Lacroix, O., Peiretti, F., Gremeaux, T., Verdier, M., Grino, M., Stepanian, A., Msika, S., Burcelin, R., de Prost, D., Tanti, J.F., and Alessi, M.C. The inflammatory receptor CD40 is expressed on human adipocytes: contribution to crosstalk between lymphocytes and adipocytes. Diabetologia 52, 1152, 2009.

20. Yi, Z., Stunz, L.L., and Bishop, G.A. CD40-mediated maintenance of immune homeostasis in the adipose tissue microenvironment. Diabetes 63, 2751, 2014.

21. Evans, R.M., Barish, G.D., and Wang, Y.X. PPARs and the complex journey to obesity. Nat Med 10, 355, 2004.

22. Imai, T., Takakuwa, R., Marchand, S., Dentz, E., Bornert, J.M., Messaddeq, N., Wendling, O., Mark, M., Desvergne, B., Wahli, W., Chambon, P., and Metzger, D. Peroxisome proliferator-activated receptor gamma is required in mature white and brown adipocytes for their survival in the mouse. Proc Natl Acad Sci U S A 101, 4543, 2004.

23. Poulsen, L.L., Siersbæk, M., and Mandrup, S. PPARs: fatty acid sensors controlling metabolism. Semin Cell Dev Biol 23, 631, 2012.

24. Bradley, R.L., Fisher, F.F., and Maratos-Flier, E. Dietary fatty acids differentially regulate production of TNF-alpha and IL-10 by murine 3T3-L1 adipocytes. Obesity 16, 938, 2008.

25. Kennedy, A., Martinez, K., Chuang, C.-C., LaPoint, K., and McIntosh, M. Saturated fatty acid-mediated inflammation and insulin resistance in adipose tissue: mechanisms of action and implications. J Nutr 139, 1, 2009.

26. Kliewer, S.A., Sundseth, S.S., Jones, S.A., Brown, P.J., Wisely, G.B., Koble, C.S., Devchand, P., Wahli, W., Willson, T.M., Lenhard, J.M., and Lehmann, J.M. Fatty acids and eicosanoids regulate gene expression through direct interactions with peroxisome proliferator-activated receptors alpha and gamma. Proc Natl Acad Sci U S A 94, 4318, 1997.

27. Xu, H.E., Lambert, M.H., Montana, V.G., Parks, D.J., Blanchard, S.G., Brown, P.J., Sternbach, D.D., Lehmann, J.M., Wisely, G.B., Willson, T.M., Kliewer, S.A., and Milburn, M.V. Molecular recognition of fatty acids by peroxisome proliferator-activated receptors. Mol Cell 3, 397, 1999.

28. Ryden, M., Dicker, A., van Harmelen, V., Hauner, H., Brunnberg, M., Perbeck, L., Lonnqvist, F., and Arner, P. Mapping of early signaling events in tumor necrosis factoralpha -mediated lipolysis in human fat cells. J Biol Chem 277, 1085, 2002.

29. Zhang, H.H., Halbleib, M., Ahmad, F., Manganiello, V.C., and Greenberg, A.S. Tumor necrosis factor-alpha stimulates lipolysis in differentiated human adipocytes through activation of extracellular signal-related kinase and elevation of intracellular cAMP. Diabetes 51, 2929, 2002.
30. Botion, L.M., Brasier, A.R., Tian, B., Udupi, V., and Green, A. Inhibition of proteasome activity blocks the ability of $\mathrm{TNF} \alpha$ to down-regulate $\mathrm{Gi}$ proteins and stimulate lipolysis. Endocrinology 142, 5069, 2001.

31. Gasic, S., Tian, B., and Green, A. Tumor necrosis factor $\alpha$ stimulates lipolysis in adipocytes by decreasing Gi protein concentrations. J Biol Chem 274, 6770, 1999.

32. Rahn Landström, T., Mei, J., Karlsson, M., Manganiello, V., and Degerman, E. Down-regulation of cyclic-nucleotide phosphodiesterase 3B in 3T3-L1 adipocytes induced by tumour necrosis factor alpha and cAMP. Biochem J 346, 337, 2000.

33. Souza, S.C., Palmer, H.J., Kang, Y.H., Yamamoto, M.T., Muliro, K.V., Paulson, K.E., and Greenberg, A.S. TNFalpha induction of lipolysis is mediated through activation of the extracellular signal related kinase pathway in 3T3-L1 adipocytes. J Cell Biochem 89, 1077, 2003.

34. Turner, P.A., Harris, L.M., Purser, C.A., Baker, R.C., and Janorkar, A.V. A surface-tethered spheroid model for functional evaluation of 3T3-L1 adipocytes. Biotechnol Bioeng 111, 174, 2014.

35. Alkhouli, N., Mansfield, J., Green, E., Bell, J., Knight, B., Liversedge, N., Tham, J.C., Welbourn, R., Shore, A.C., Kos, K., and Winlove, C.P. The mechanical properties of human adipose tissues and their relationships to the structure and composition of the extracellular matrix. Am J Physiol Endocrinol Metab 305, E1427, 2013.

36. Kotani, A., Fuse, T., and Kusu, F. Determination of plasma free fatty acids by high-performance liquid chromatography with electrochemical detection. Anal Biochem 284, 65, 2000.

37. McPherson, D.T., Xu, J., and Urry, D.W. Product purification by reversible phase transition following Escherichia coli expression of genes encoding up to 251 repeats of the elastomeric pentapeptide GVGVP. Protein Expr Purif 7, 51, 1996.

38. Turner, P.A., Weeks, C.A., McMurphy, A.J., and Janorkar, A.V. Spheroid organization kinetics of H35 rat hepatoma model cell system on elastin-like polypeptidepolyethyleneimine copolymer substrates. J Biomed Mater Res Part A 102, 852, 2014.

39. Todaro, G.J., and Green, H. Quantitative studies of the growth of mouse embryo cells in culture and their development into established lines. J Cell Biol 17, 299, 1963.

40. Bligh, E.G., and Dyer, W.J. A rapid method of total lipid extraction and purification. Can J Biochem Physiol 37, 911, 1959.

41. Guilherme, A., Virbasius, J.V., Puri, V., and Czech, M.P. Adipocyte dysfunctions linking obesity to insulin resistance and type 2 diabetes. Nat Rev Mol Cell Biol 9, 367, 2008.

42. Jensen, M.D. Adipose tissue as an endocrine organ: implications of its distribution on free fatty acid metabolism. Eur Heart J Suppl 8, B13, 2006.

43. Subauste, A.R., and Burant, C.F. Role of FoxO1 in FFAinduced oxidative stress in adipocytes. Am J Physiol Endocrinol Metab 293, E159, 2007.

44. Ailhaud, G. Development of white adipose tissue and adipocyte differentiation. In: Klaus, S., ed. Adipose Tissues. Austin, TX: Eurekah.com Inc., 2001, p. 27.

45. Sauma, L., Stenkula, K.G., Kjølhede, P., Strålfors, P., Söderström, M., and Nystrom, F.H. PPAR- $\gamma$ response element activity in intact primary human adipocytes: effects of fatty acids. Nutrition 22, 60, 2006.

46. Dordevic, A.L., Konstantopoulos, N., and Cameron-Smith, D. 3T3-L1 preadipocytes exhibit heightened monocyte- 
chemoattractant protein-1 response to acute fatty acid exposure. PLoS One 9, e99382, 2014.

47. Bueno, A., Oyama, L., de Oliveira, C., Pisani, L., Ribeiro, E., Silveira, V., and Oller do Nascimento, C. Effects of different fatty acids and dietary lipids on adiponectin gene expression in 3T3-L1 cells and C57BL/6J mice adipose tissue. Pflugers Arch 455, 701, 2008.

48. Granados, N., Amengual, J., Ribot, J., Palou, A., and Bonet, M.L. Distinct effects of oleic acid and its trans-isomer elaidic acid on the expression of myokines and adipokines in cell models. Br J Nutr 105, 1226, 2011.

49. Plomgaard, P., Fischer, C.P., Ibfelt, T., Pedersen, B.K., and van Hall, G. Tumor necrosis factor- $\alpha$ modulates human in vivo lipolysis. J Clin Endocrinol Metab 93, 543, 2008.

50. Souza, S.C., de Vargas, L.M., Yamamoto, M.T., Lien, P., Franciosa, M.D., Moss, L.G., and Greenberg, A.S. Overexpression of perilipin A and B blocks the ability of tumor necrosis factor $\alpha$ to increase lipolysis in 3T3-L1 adipocytes. J Biol Chem 273, 24665, 1998.

51. Kurebayashi, S., Sumitani, S., Kasayama, S., Jetten, A.M., and Hirose, T. TNF-alpha inhibits 3T3-L1 adipocyte differentiation without downregulating the expression of $\mathrm{C} /$ EBPbeta and delta. Endocr J 48, 249, 2001.

52. Lien, C.C., Au, L.C., Tsai, Y.L., Ho, L.T., and Juan, C.C. Short-term regulation of tumor necrosis factor-alpha- induced lipolysis in 3T3-L1 adipocytes is mediated through the inducible nitric oxide synthase/nitric oxide-dependent pathway. Endocrinology 150, 4892, 2009.

53. Ruan, H., Hacohen, N., Golub, T.R., Van Parijs, L., and Lodish, H.F. Tumor necrosis factor-alpha suppresses adipocyte-specific genes and activates expression of preadipocyte genes in 3T3-L1 adipocytes: nuclear factorkappaB activation by TNF-alpha is obligatory. Diabetes 51, 1319, 2002.

54. Beale, E.G., Hammer, R.E., Antoine, B., and Forest, C. Glyceroneogenesis comes of age. FASEB J 16, 1695, 2002.

Address correspondence to: Amol V. Janorkar, PhD

Department of Biomedical Materials Science School of Dentistry University of Mississippi Medical Center 2500 North State Street Jackson, MS 39216

E-mail: ajanorkar@umc.edu

Received: September 5, 2014

Accepted: February 23, 2015

Online Publication Date: April 20, 2015 


\section{This article has been cited by:}

1. Shoichiro Sumi, Masako Kawagoe, Rie Abe, Goichi Yanai, Kai-Chiang Yang, Yasumasa Shirouzu. 2017. A multiple-funnels cell culture insert for the scale-up production of uniform cell spheroids. Regenerative Therapy 7, 52. [Crossref]

2. Sasha Cai Lesher-Pérez, Ge-Ah Kim, Chuan-hsien Kuo, Brendan M. Leung, Sanda Mong, Taisuke Kojima, Christopher Moraes, M. D. Thouless, Gary D. Luker, Shuichi Takayama. 2017. Dispersible oxygen microsensors map oxygen gradients in threedimensional cell cultures. Biomaterials Science 5:10, 2106-2113. [Crossref]

3. Rosalyn D. Abbott, Rebecca Y. Wang, Michaela R. Reagan, Ying Chen, Francis E. Borowsky, Adam Zieba, Kacey G. Marra, J. Peter Rubin, Irene M. Ghobrial, David L. Kaplan. 2016. The Use of Silk as a Scaffold for Mature, Sustainable Unilocular Adipose 3D Tissue Engineered Systems. Advanced Healthcare Materials 5:13, 1667-1677. [Crossref]

4. Francisco Ruiz-Ojeda, Azahara Rupérez, Carolina Gomez-Llorente, Angel Gil, Concepción Aguilera. 2016. Cell Models and Their Application for Studying Adipogenic Differentiation in Relation to Obesity: A Review. International Journal of Molecular Sciences 17:7, 1040. [Crossref]

5. Temenoff Johnna S.. 2016. Special Collection: Emerging Concepts in Three-Dimensional Microtissues. Tissue Engineering Part A 22:1-2, 3-4. [Abstract] [Full Text HTML] [Full Text PDF] [Full Text PDF with Links]

6. Maryse Proulx, Meryem Safoine, Dominique Mayrand, Kim Aubin, Amandine Maux, Julie Fradette. 2016. Impact of TNF and IL-1 $\beta$ on capillary networks within engineered human adipose tissues. Journal of Materials Chemistry B 4:20, 3608-3619. [Crossref] 